\title{
Revised National Tuberculosis Control Programme (RNTCP) Tribal Action Plan Fund Utilisation: How Does Chhattisgarh State in India Fare?
}

\section{Gayadhar Mallick ${ }^{*}$, Sharath Burugina Nagaraja ${ }^{2}$, Karuna D. Sagili', Kshitij Khaparde ${ }^{3}$, Srinath Satyanarayana ${ }^{1}$, Sarabjit Chadha ${ }^{1}$}

\author{
${ }^{1}$ The International Union against TB and Lung Disease, New Delhi, India \\ ${ }^{2}$ ESIC Medical College and PGIMSR, Bangalore, India \\ ${ }^{3}$ WHO Country Office, New Delhi, India \\ Email: *GMallick@theunion.org
}

How to cite this paper: Mallick, G., Nagaraja, S.B., Sagili, K.D., Khaparde, K., Satyanarayana, S. and Chadha, S. (2019) Revised National Tuberculosis Control Programme (RNTCP) Tribal Action Plan Fund Utilisation: How Does Chhattisgarh State in India Fare? Journal of Tuberculosis Research, 7 , 1-10.

https://doi.org/10.4236/jtr.2019.71001

Received: November 7, 2018

Accepted: January 13, 2019

Published: January 17, 2019

Copyright $\odot 2019$ by authors and Scientific Research Publishing Inc. This work is licensed under the Creative Commons Attribution International License (CC BY 4.0).

http://creativecommons.org/licenses/by/4.0/

\begin{abstract}
Background: In India, tuberculosis remains as a major public health problem amongst the tribal population. Poor physical access to diagnosis and treatment under the Revised National TB control programme (RNTCP) still remains the problem for the population. RNTCP implements Tribal Action Plan (TAP) for tribal patients. We conducted the study to determine the trends of financial utilisation for the special provisions available under tribal action plan like patient honorarium, incentive for sputum collection and transport, incentive for programme staff and incentive for vehicle maintenance. Methods: A cross-sectional study based on mixed method study approach was conducted in Chhattisgarh, India during Nov. 16 to Jun. 17. District TB Officers implementing TAP were interviewed telephonically using a semi-structured questionnaire to ascertain and analyse the reasons for low fund utilization in their districts. Retrospective financial data for five financial years from 13 TAP districts for 2012-2013 to 2016-2017 was collected, compiled and analysed. Results: Overall, the trends on states expenditure on tribal action plan in terms of absolute numbers has increased over the past five years; however, in terms of fund utilization against received ranges from $37 \%$ - $86 \%$ with the utilization rate less than $44 \%$ in the recent years (2014-2017). Conclusion: The trend of utilisation of TAP is less than $44 \%$ over the recent years. There is an urgent need for the administrators to intervene and improve the efficiency of fund utilisation at State and district levels.
\end{abstract}




\section{Keywords}

Fund, Tuberculosis, Tribal Action Plan, RNTCP, India

\section{Introduction}

Globally, tuberculosis remains a major public health problem and India contributes to more than $27 \%$ of the TB burden [1]. It is evident that the tribal population is more affected with tuberculosis when compared to the general population [2] [3]. There are 104 million tribal people ( $8.6 \%$ of the population) in the country [4]. These sections of tribal population are considered to be the most disadvantaged group socio-economically. They generally reside in hilly and difficult to reach areas. The availability and utilisation of health care services remains a challenge; demand side barriers, structural constraints, human resource issues and the provider attitudes are particularly acute in tribal areas [5] [6] [7]. Out of the 400 tribal groups in the country, nearly 50\% live in the states of Arunachal Pradesh, Meghalaya, Mizoram, Nagaland, Lakshadweep and Dadra and Nagar Haveli while more than $40 \%$ are concentrated in the following nine states viz., Jharkhand, Rajasthan, Chhattisgarh, Odisha, Andhra Pradesh, Assam, Gujarat, Maharashtra and West Bengal [8] [9].

The TB disease prevalence survey conducted by the Regional Medical Research Centre for Tribals, Jabalpur (RMRCT) showed a high prevalence of TB disease (1518/100,000 population) [10]. The RNTCP has prioritized these tribal population as "special populations and hard to reach" groups for service delivery. The programme has sustained focus to provide effective and quality services for the tribal population; it has made several special norms and guidelines through tribal action plan (TAP) for better implementation in the tribal areas that includes more incentives, human resources and decreased population norms by $50 \%$ for designated microscopy centres (DMCs) when compared with the norms for plain areas (NSP 2012-17) [11]. The special services implemented under RNTCP TAP mainly includes 1) patient honorarium: It is the monetary benefit provided to the patients on completing their TB treatment 2) Incentive for psutum collection and transport: It is the monetary benefits for the personnel (volunteer or general health staff) who is involved in collecting sputum sample of the patients from their residence to the designated microscopy centre 3) incentive for programme staff: It is the additional allowances provided to the programme contractual staff namely the senior treatment supervisor (STS), senior TB laboratory supervisor (STLS) and labortory technician (LT) for working in hard-to-reach areas. They are responsible for monitoring the TB treatment and quality of laboratory services at designated microscopy centres under a defined geographical population of 0.5 million. The programme provides one two-wheeler vehicle for these two staffs to facilitate them in performing their duties efficiently 4) incentive for vehicle maintenance: It is the additional allowances provided to 
RNTCP contractual staff to support the cost of fuel involved in monitoring of the patients and the annual vehicular maintenance.

\section{The Process of Fund Flow under RNTCP}

Healthcare in India is one of the large service sectors; the Government of India (GoI) delivers public health services through a flagship scheme called National Health Mission (NHM) and RNTCP is one of its sub-components. The Ministry of Health and Family Welfare (MoHFW), GoI follows equity based approach to allocate funds under RNTCP to various states. The principles for allocation of funds to the states are based on its population, disease burden and socio-economic status. The process of fund delivery from national level to the districts is as described. The financial cycle begins with the districts developing the project implementation plan (PIP) and submitting to the state in the month of October, the state compiles all the district plans and submit to NHM in the month of December, while the state NHM compiles the PIP from all the disease control programmes and submits to central NHM in February. The National Coordination Committee reviews the state PIPs and provides approval as record of proceedings (RoP) to the states in the month of March. The State NHM releases the first instalment of approved budget to the district NHM in the month of March and subsequently the district health society release the budget to the district health society (sub-society TB) for utilisation in the month of April. The districts start expediting the planned activities from the month of May.

Despite the implementation of Revised National TB Control Programme (RNTCP) tribal action plan (TAP) since May 2005 onwards; these tribal communities continue to face multiple challenges including access to TB diagnostic and treatment services [12]. The programme has clearly overlaid the special financial provisions for implementaion of RNTCP TAP in the tribal districts. However, there is sparse information available about the TAP fund utilisation at state and districts and the challenges encountered by the programme personnel in managing these funds.

The state of Chhattisgarh is located in central India and has a population of 29.2 million. The state with 16 districts was formed in November 2000 after being carved out from the state of Madhya Pradesh. Subsequently, 27 administrative districts were formed out of these original 16 wherein most of the districts implementing TAP districts were formed during 2012-13. Nearly one-third population of the state belongs to tribal population and the state is home for 42 types of tribes and most of this population is concentrated in 15 districts [9]. The health status of these tribes are extremely poor due to long lasting malnutrition, lack of proper hygiene, illiteracy and their archetypal age-old health seeking behaviour [13]. We conducted this study in Chhattisgarh state, India to determine the trends of financial utilisation for the special provisions made under the tribal action plan and to determine the challenges faced by programme personnel for fund utilisation while implementing TAP. 


\section{Methods}

We conducted a cross-sectional study during November 2016 through June 2017 in the state of Chhattisgarh based on mixed method study approach.

\subsection{Settings}

The state of Chhattisgarh has nearly 29 million populations spread across 27 administrative districts. Of these 27 districts, 15 are tribal districts with predominant tribal population and 12 are non-tribal districts. We included 13 tribal districts for our study.

The study included review of RNTCP financial records and reports at state TB office and district tuberculosis centres with interview of key programme personnel at the district level. Based on the feasibility and convenience for conduct of the study we included thirteen districts for the study. The District TB Officers implementing TAP were interviewed telephonically using a semi-structured questionnaire to ascertain the challenges faced for fund utilisation in their districts. Retrospective financial data for five financial years from thirteen TAP districts for 2011-13 to 2016-17 was collected, compiled and analysed.

\subsection{Study Variables}

For the purpose of the study the following variables were included 1) budget proposed by the districts in PIP 2) budget approved by NHM to districts based on RoP and 3) budget utilized by the districts for the delivery of following TAP activities: a) honorarium b) incentive for sputum collection and transport c) incentive for programme staff and d) incentive for vehicle maintenance. The retrospective financial data for the past five financial years (FY) (FY 2012-13 to 2016-17) were collected from the Project implementation plan (PIP), statement of expenditure (SOE) and audited reports of these districts. Cross-validation of the data was done with NHM records both at the district and state level finance departments.

\subsection{Data Collection and Analysis}

The data was collected electronically using a Microsoft excel sheet. The data analysis was performed to obtain the percentages and proportions using STATA (version 11) software.

\subsection{Ethics Approval}

The ethics approval was obtained by The Union Ethics Advisory Group, Paris, France. The administrative approval for the conduct of the study was obtained from the RNTCP State TB Cell, Directorate of Health Services, Raipur, Chhattisgarh.

\section{Results}

Overall, the trends on states expenditure on tribal action plan in terms of abso- 
lute numbers has increased over the past five years; however, in terms of fund utilization against received ranges from $37 \%-86 \%$ with the utilization rate less than $44 \%$ in the recent years (2014-17) (Figure 1). The absolute figures for utilization in Indian rupees (in million) and the proportion of expenditure for the financial year (FY) beginning from $1^{\text {st }}$ of April to $31^{\text {st }}$ of March for different components of TAP are shown in Table 1.

The expenditure for the components of TAP is as described below (Figure 2):

1) Patient honorarium: The proportion of expenditure ranged from $25 \%$ $60 \%$ with the utilization rate less than $33 \%$ in recent years

2) Sputum collection transport. The proportion of expenditure ranged from $19 \%-80 \%$ with the utilization rate less than $37 \%$ in recent years

3) Staff incentive: The proportion of expenditure ranged from $50 \%-76 \%$ with the utilization rate less than $56 \%$ in recent years

4) Vehicle maintenance: The proportion of expenditure ranged from $28 \%$ $60 \%$ with the utilization rate less than $48 \%$ in recent years

The trends of fund utilisation among the districts are shown in the Figure 3 and Table 2.

\section{Challenges Faced for TAP Fund Utilisation}

The challenges encountered by the key programme personnel are shown in Table 3. The main reasons cited under general challenges included areas infested with Naxalites, scarcity of funds along with procedural delays for optimal utilization. While, the challenges for utilisation under TAP components were complex mechanism of disbursement, no activity due to short fall of staff, vacancies of contractual staff positions and non-availability of funds.

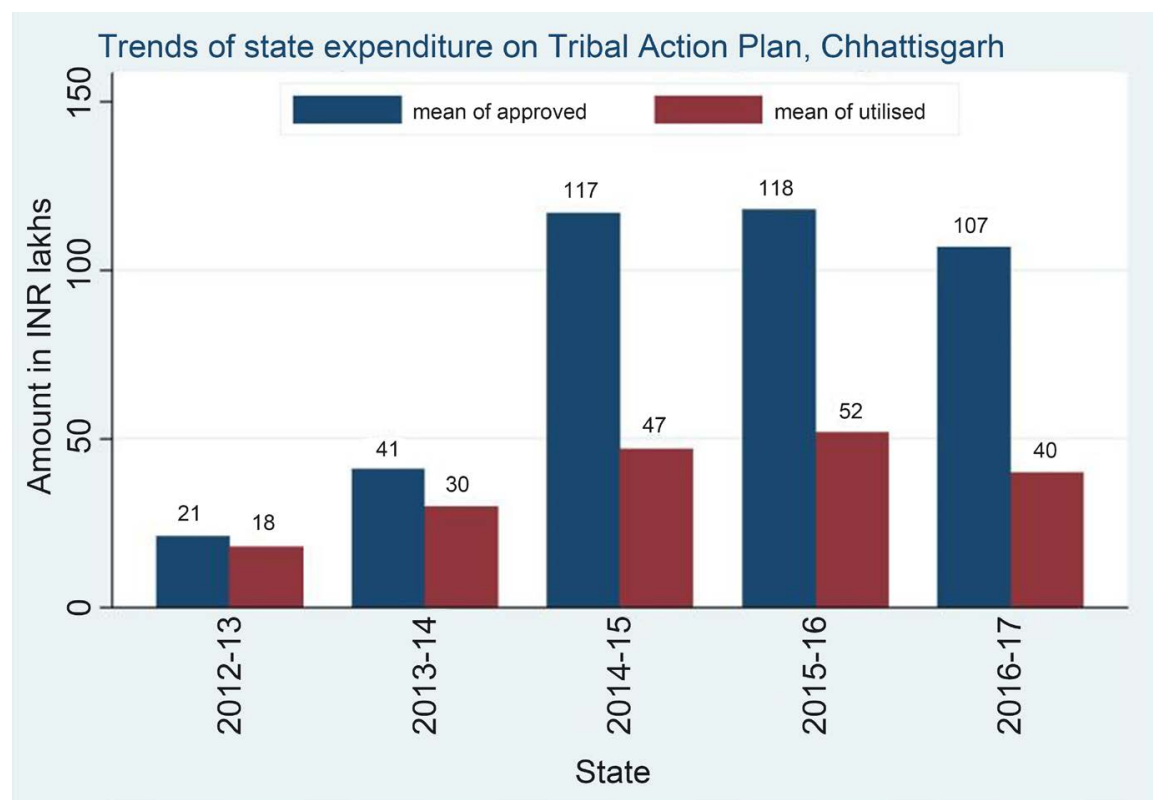

Figure 1. Trends of funds approved and utilised under RNTCP Tribal Action Plan (2012-17) Chattisgarh, India. 
Table 1. The absolute figures for utilization and the proportion of expenditure for different components of RNTCP TAP, Chattisgarh, India.

\begin{tabular}{|c|c|c|c|c|c|c|c|c|c|c|}
\hline \multirow[b]{2}{*}{$\begin{array}{c}\text { Financial } \\
\text { year }\end{array}$} & \multicolumn{2}{|c|}{ State } & \multicolumn{2}{|c|}{$\begin{array}{c}\text { Patient } \\
\text { honorarium }\end{array}$} & \multicolumn{2}{|c|}{$\begin{array}{c}\text { Sputum collection } \\
\text { transport }\end{array}$} & \multicolumn{2}{|c|}{$\begin{array}{c}\text { Staff } \\
\text { incentive }\end{array}$} & \multicolumn{2}{|c|}{$\begin{array}{c}\text { Vehicle } \\
\text { maintenance }\end{array}$} \\
\hline & 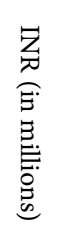 & 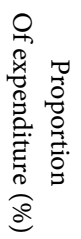 & 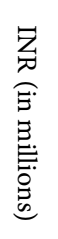 & 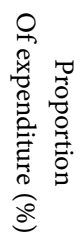 & 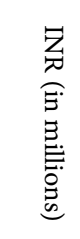 & 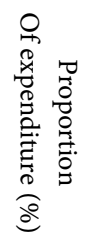 & 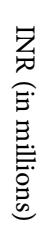 & 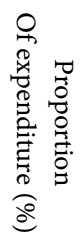 & 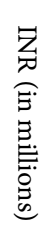 & $\begin{array}{l}0 \\
0 \\
0 \\
0 \\
0 \\
0 \\
0 \\
0 \\
0 \\
0 \\
0 \\
0 \\
0 \\
0 \\
0 \\
0\end{array}$ \\
\hline $2012-13$ & 1.8 & 86 & 0.6 & 50 & 0.2 & NA & 0.9 & 75 & 0.3 & 100 \\
\hline 2013-14 & 3.0 & 73 & 0.6 & 60 & 0.4 & 80 & 1.6 & 76 & 0.5 & 100 \\
\hline 2014-15 & 4.7 & 40 & 0.8 & 27 & 0.3 & 19 & 1.6 & 54 & 1.9 & 48 \\
\hline $2015-16$ & 5.2 & 44 & 1.1 & 33 & 0.4 & 31 & 1.8 & 56 & 1.9 & 48 \\
\hline 2016-17 & 10.7 & 37 & 1.1 & 25 & 0.6 & 37 & 1.4 & 50 & 1.0 & 28 \\
\hline
\end{tabular}

(INR-Indian rupees).

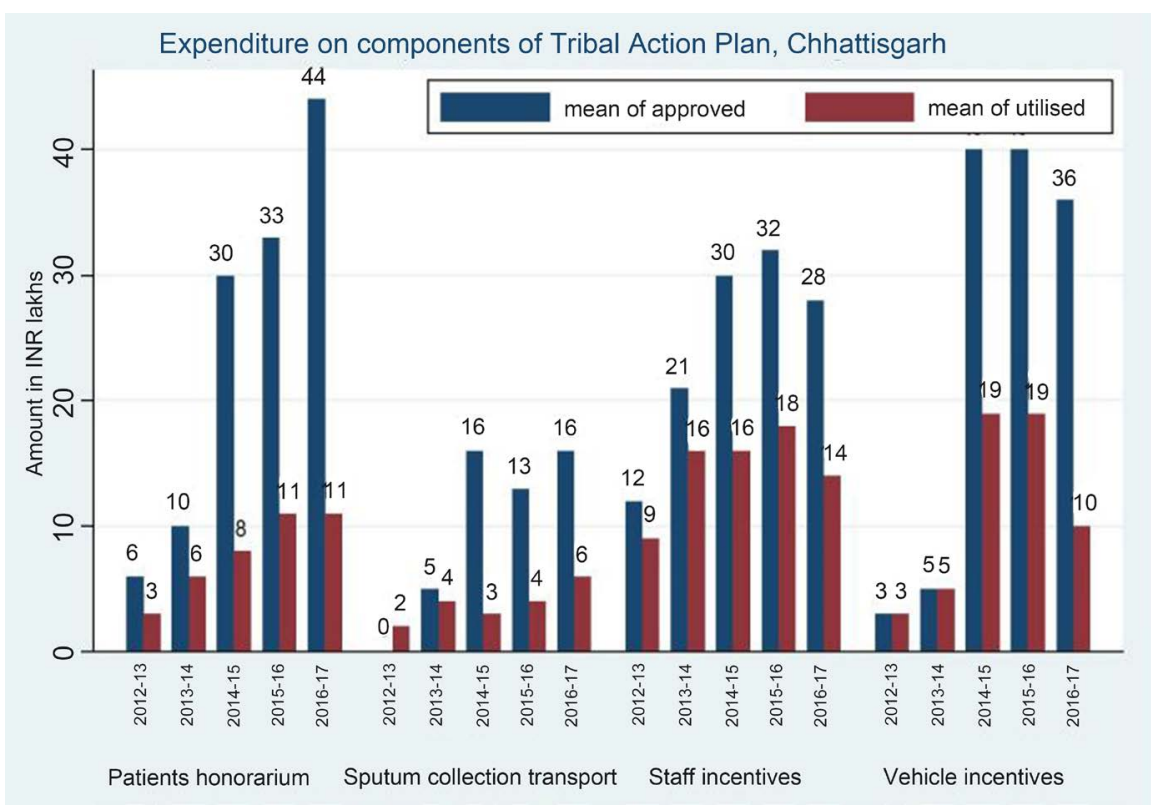

Figure 2. Expenditure on components of RNTCP Tribal Action Plan (2012-17), Chattisgarh, India.

Table 2. Tribal District groups based on the trend of financial utilisation pattern from past five years (2012-17), Chattisgarh, India $(\mathrm{N}=13)$.

\begin{tabular}{|c|c|c|c|}
\hline \multirow{2}{*}{$\begin{array}{c}\text { Proportion of } \\
\text { finance utilisation }\end{array}$} & \multicolumn{3}{|c|}{ Funds approved in absolute numbers } \\
\hline & Increased & Decreased & No change \\
\hline Increased & $\begin{array}{l}\text { Dantewada, } \\
\text { Gariyabandh }\end{array}$ & - & - \\
\hline Decreased & Koriya, Balarampur & $\begin{array}{c}\text { Bastar, Bijapur, Kondagaon, } \\
\text { Korba }\end{array}$ & - \\
\hline No change & $\begin{array}{l}\text { Kanker, Surguja, } \\
\text { Surajpur }\end{array}$ & - & Narayanpur, Sukma \\
\hline
\end{tabular}




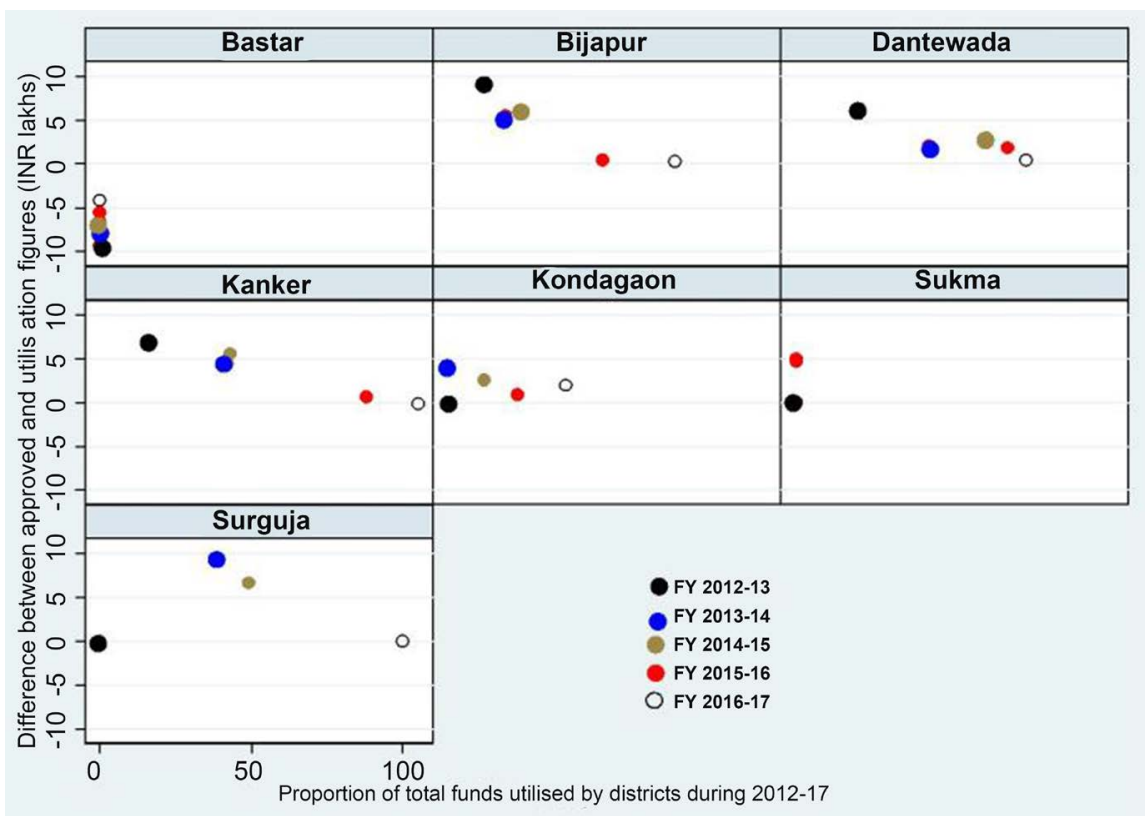

Figure 3. Graph showing the pattern of utilisation of TAP funds during financial years 2012-17, Chattisgarh, India.

Table 3. Challenges faced by programme personnel for fund utilization under RNTCP TAP, Chattisgarh, India.

\begin{tabular}{lc}
\multicolumn{1}{c}{ Challenges for fund utilization } & Respondents (N = 13) \\
\hline General challenges & 11 \\
- Districts are Naxalite affected & 9 \\
- Scarcity of funds for TAP implementation & 8 \\
- Procedural delays for optimal utilisation & 13 \\
Patients Honorarium & 1 \\
- Complex mechanism of disbursement & \\
- Adequate funds were not available & 2 \\
Sputum collection and transport & 9 \\
- No activity due to short fall of staff & 9 \\
- Delay in disbursement of funds & \\
- Incentive paid was considered meagre & 4 \\
Staff incentive & 9 \\
- Vacancies of contractual staff positions & \\
- Untimely or no submission of vehicle utilisation records by staff & \\
Vehicle maintenance & 7 \\
- Non-availability of funds & 5 \\
- Non-functioning vehicles due to shortage of contractual staff & \\
\hline
\end{tabular}

\section{Discussion}

It is one of the first studies in India to describe the trends in financial utilization of the approved budget in the districts implementing tribal action plan of RNTCP. The important finding of the study is that though there is substantial increase in the funds approved and funds utilised at the districts, the overall proportion of funds utilised has less than $44 \%$ (37 - 86) in the recent years. Except for the staff incentive component of the TAP the proportion of expenditure 
has remained less than $50 \%$. This is a worrisome factor for the programme as the envisioned health care services are not being efficiently delivered to the tribal population and calls for immediate attention of the administrators to stream line the financial management.

The standard financial processing cycle for the states under the Ministry of Health and Family Welfare, Government of India is to develop a project implementation plan for the RNTCP at the district level which gets merged with all other health programmes at the districts and submitted for financial approval at state and central level. In general, the approved funds for the states and districts are released in 2 - 4 instalments during the financial year upon receipt of statement of expenditure on quarterly basis. Though, the state of Chhattisgarh had followed the planning cycle and had received the funds in the said quarters there has been delay in flow of funds which has led to decrease in available time frame for programme managers to expend the funds. The low utilisation of funds below the district level could also be due to perennial health issues that have been prevalent in these areas. The majority of these districts are Naxalites infested areas and the delivery of health services may have issues with the penetration of the programmes at the community level.

We briefly discuss about the probable issues pertaining to the components of TAP, while some of the views expressed here is based on the authors experience in the field and the reflections gathered while interacting with programme managers. 1) Patient honorarium: The patients are incentivised on completing their full treatment. The mechanism for this incentive approach is that the field staff collects the list of tuberculosis patients who have completed their treatment and their bank account details for direct fund transfers from the community treatment providers and submits it to the district TB officer for further disbursement of incentives. The district TB officer after obtaining the approval from the district chairman of health society, will transfer the funds to the gram panchayat office for disbursement through their secretary to those eligible TB patients. The mechanism seems to be complex and there seems to be delays at many levels during this process. At times, the funds are not disbursed due to non-approval by gram panchayat office and frequent instances of shortages in fund availability. 2) Sputum collection and transportation: This activity requires establishment of sputum collection centres at different location and transport the collected sputum to designated microscopy centres at regular intervals from these locations. This activity is more suitable for community volunteers or general health staff to perform. Lack of adequate community volunteers or general health staff at remote areas who can perform this activity has led to low utilisation and for those few who perform the activity there is delay in payments for the activity performed. The amount offered by the programme for this activity is not attractive. 3) Staff incentive: The RNTCP programme personnel (senior treatment supervisors (STS), senior treatment laboratory supervisor (STLS) and laboratory technicians) are provided an incentive for performing their duties at hard to reach areas. This component is comparatively well utilized compared to other 
TAP components. The contractual staff vacancies has been a challenge for programme managers to utilise this component effectively. 4) Vehicle maintenance: The STS are provided with a two wheeler by the programme for treatment monitoring in the field and they are provided incentives for fuel and maintenance of the vehicles. The reimbursement process involves the staffs submitting their log books and tour reports to the district TB officers which after verification are processed for release of the amount. The delay by programme personnel's in submitting the vehicle log books and related documents to programme managers for reimbursement and vacancies in contractual positions has been a challenge to programme managers for effective utilisation.

The strength of this study is that the figures are derived from the programmatic documents which otherwise is not publicly available and reflects the ground realities under programmatic conditions. However, the limitation is that the study is from thirteen districts of Chhattisgarh and the findings cannot be generalised to other field settings elsewhere in the country. Further research is needed to ascertain the process related issues in these settings and areas.

To improve the utilisation of the funds, the programme has to strengthen the capacity of health systems for utilisation. Broadly, 1) at the planning level: the programme implementation plan has to be realistic and meticulously plan based on the programme needs and priorities. The programme managers should have clarity on the ways to utilise the approved budget for the planned activities; 2) at the level of utilisation: there should be adequate staff made available from the general health system at places where there is deficiency of key RNTCP staff. There should be innovative simple mechanism to ensure quick payments to the patients and the programme staff.

\section{Conclusion}

The trend of utilisation of TAP is less than $44 \%$ over the recent years. There is an urgent need for the administrators to intervene and improve the efficiency of fund utilisation at State and district levels.

\section{Acknowledgements}

The manuscript was developed as part of the National Operational Research Course (2016-17) conducted by The Union in collaboration with National TB Institute, Bangalore; Central TB Division, Ministry of Health and Family Welfare, Government of India; CDC, Atlanta and WHO country office, India. We acknowledge the support rendered by the State TB Office of Chhattisgarh for the conduct of the study. We also thank all the District TB officers and RNTCP staff of Chhattisgarh state who formed the part of our study group. Special thanks to M V Ajay Kumar, The Union for his guidance to develop the protocol.

\section{Conflicts of Interest}

The authors declare no conflicts of interest regarding the publication of this paper. 


\section{References}

[1] WHO (2016) Global Tuberculosis Report 2016. http://scholar.google.com/scholar?hl=en\&btnG=Search\&q=intitle:No+Title\#0

[2] Thomas, B.E., Adinarayanan, S., Manogaran, C. and Swaminathan, S. (2015) Pulmonary Tuberculosis among Tribals in India: A Systematic Review \& Meta-Analysis. Indian Journal of Medical Research, 141, 614-623.

http://www.ncbi.nlm.nih.gov/pubmed/26139779

[3] Kashyap, R., Nayak, A., Husain, A., Shekhawat, S., Satav, A., Jain, R., et al. (2016) Impact of Socioeconomic Status and Living Condition on Latent Tuberculosis Diagnosis among the Tribal Population of Melghat: A Cohort Study. Lung India, 33, 372. http://www.lungindia.com/text.asp?2016/33/4/372/184868

[4] Office of the Registrar General \& Census Commissioner (2011) Census of India: Scheduled Castes and Scheduled Tribes.

http://censusindia.gov.in/Census_And_You/scheduled_castes_and_sceduled_tribes. aspx

[5] Muniyandi, M., Rao, V.G., Bhat, J. and Yadav, R. (2015) Performance of Revised National Tuberculosis Control Programme (RNTCP) in Tribal Areas in India. Indian Journal of Medical Research, 141, 624-629.

http://www.ncbi.nlm.nih.gov/pubmed/26139780

[6] Rawal, S.V. (2014) RNTCP in Gujarat: A Comparative Study between Tribal and Non-Tribal Areas. Indian Journal of Tuberculosis, 61, 129-133.

http://www.ncbi.nlm.nih.gov/pubmed/25509935

[7] Addlakha, R. and Seeberg, J. (2004) Accessing TB Services in a Tribal District. Orissa. http://pure.au.dk/portal/files/69920781/Malkangiri_fulltext.pdf

[8] (2014) Tribal Profile at a Glance. http://www.tribal.nic.in/ST/Tribal Profile.pdf

[9] Population-Size \& Distribution. http://censusindia.gov.in/Tables_Published/SCST/dh_st_chhattisgarh.pdf

[10] Rao, V.G., Gopi, P.G., Bhat, J., Selvakumar, N., Yadav, R., Tiwari, B., Gadge, V., Bhondeley, M.K. and Wares, F. (2010) Pulmonary Tuberculosis: A Public Health Problem amongst the Saharia, a Primitive Tribe of Madhya Pradesh, Central India. International Journal of Infectious Diseases, 14, e713-e716. https://doi.org/10.1016/j.ijid.2010.02.2243

[11] Sachdeva, K.S., Kumar, A., Dewan, P., Kumar, A. and Satyanarayana, S. (2012) New Vision for Revised National Tuberculosis Control Programme (RNTCP): Universal Access-"Reaching the Un-Reached". Indian Journal of Medical Research, 135, 690-694. http://www.ncbi.nlm.nih.gov/pubmed/22771603

[12] Basa, S. and Venkatesh, S. (2016) Patient and Healthcare System Delays in the Start of Pulmonary Tuberculosis Treatment among Tribal Patients Registered under DOTS, Odisha. Journal of Clinical and Diagnostic Research, 10, LC21-LC24. http://www.ncbi.nlm.nih.gov/pubmed/27790474

[13] Basu, S. (2000) Dimensions of Tribal Health in India. Health and Population-Perspectives and Issues, 23, 61-70. http://medind.nic.in/hab/t00/i2/habt00i2p61.pdf 